\title{
Crigler-Najjar Syndrome
}

National Cancer Institute

\section{Source}

National Cancer Institute. Crigler-Najjar Syndrome. NCI Thesaurus. Code C84656.

A rare autosomal recessive inherited syndrome characterized by abnormalities in the metabolism of bilirubin. It results in the development of jaundice. It may cause brain damage in infancy. 